Supporting Information

\title{
Conversion of Paper and Food-rich Municipal Solid Waste Streams to Ethanol through Bioprocessing
}

Jipeng Yan ${ }^{1}$, Ling Liang ${ }^{1}$, Qian He ${ }^{1}$, Carolina Gutierrez ${ }^{1}$, Chia-Hsi Chu², Todd R. Pray ${ }^{1}$, and Ning Sun ${ }^{1^{*}}$

${ }^{1}$ Advanced Biofuels and Bioproducts Process Development Unit, Biological Systems and Engineering Division, Lawrence Berkeley National Laboratory, 5885 Hollis St,

Emeryville, CA 94608, USA

${ }^{2}$ Recology, 250 Executive Park Blvd, Suite 2100, San Francisco, CA 94134, USA

*E-mail: nsun@lbl.gov

Contents of the Supporting Information

Total number of pages: 2

Total number of figures: 1

Total number of tables: 1 

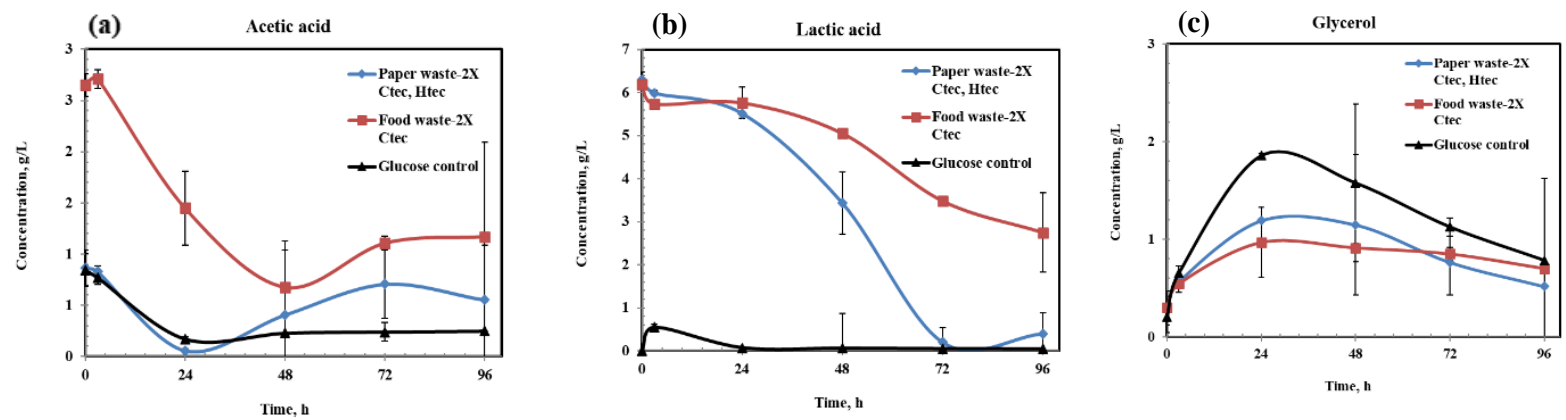

Figure S1. Acetic acid, lactic acid, and glycerol variation during hydrolysate fermentation

Table S1. Free sugars and acids present in the wet MSW samples

\begin{tabular}{|c|c|c|c|c|c|}
\hline Sample & $\begin{array}{c}\text { Free } \\
\text { glucose* } \\
(\mathrm{g} / \mathrm{L})\end{array}$ & $\begin{array}{c}\text { Free } \\
\text { fructose* } \\
(\mathrm{g} / \mathrm{L})\end{array}$ & $\begin{array}{c}\text { Free } \\
\text { sucrose* }^{*}(\mathrm{~g} / \mathrm{L})\end{array}$ & $\begin{array}{c}\text { Acetic } \\
\text { acid } \\
(\%)\end{array}$ & $\begin{array}{c}\text { Lactic } \\
\text { acid } \\
(\%)\end{array}$ \\
\hline $\begin{array}{l}\text { Paper-Rich } \\
\text { MSW }\end{array}$ & 1.3 & 1.5 & 0.3 & 0.9 & 0.3 \\
\hline Food-rich MSW & 15.4 & 14.5 & 7.9 & 1.6 & 1.6 \\
\hline
\end{tabular}

*Sugars present in the liquid portion of the streams 